\title{
Maurizio Gotti, Stefania Maci, Michele Sala (eds.), Insights into Medical Communication
}

Bern, Berlin, Brussels, Frankfurt am Main, New York, Oxford, Vienna:

Peter Lang, 2015

Jean-Pierre Charpy

\section{(2) OpenEdition}

\section{Journals}

Electronic version

URL: http://journals.openedition.org/asp/4739

DOI: $10.4000 /$ asp.4739

ISSN: 2108-6354

Publisher

Groupe d'étude et de recherche en anglais de spécialité

\section{Printed version}

Date of publication: 23 October 2015

Number of pages: 121-131

ISSN: 1246-8185

Electronic reference

Jean-Pierre Charpy, « Maurizio Gotti, Stefania Maci, Michele Sala (eds.), Insights into Medical Communication», ASp [Online], 68 | 2015, Online since 23 October 2015, connection on 02 November 2020. URL : http://journals.openedition.org/asp/4739 ; DOI : https://doi.org/10.4000/asp.4739

This text was automatically generated on 2 November 2020

Tous droits réservés 
Maurizio Gotti, Stefania Maci, Michele Sala (eds.), Insights into Medical Communication

Bern, Berlin, Brussels, Frankfurt am Main, New York, Oxford, Vienna:

Peter Lang, 2015

Jean-Pierre Charpy

\section{REFERENCES}

Gotti, Maurizio, Stefania Maci \& Michele Sala (eds.). 2015. Insights into Medical Communication. Bern, Berlin, Brussels, Frankfurt am Main, New York, Oxford, Vienna: Peter Lang, Linguistic Insights 203. 422 pp. ISBN 978-3-0343-1694-1. 
1 Medical discourse is a multifaceted object of research. It has been the object of indepth investigations from both a synchronic (Gotti \& Salager-Meyer 2006) and diachronic (Taavitsainen \& Pahta 2004, 2011) viewpoint. Thus, classic genres associated with traditional medical research (the research article, the abstract, letters to the editor, the conference presentation) and clinical practice (doctor-patient conversations, the referral letter) have generated a vast literature, often dominated by purely linguistic approaches. However, new forms of interactive communication and such newfangled genres as blogs, tweets, wikis or electronic patient information leaflets, which involve both professionals (medical doctors or interns, healthcare providers) and non-professionals

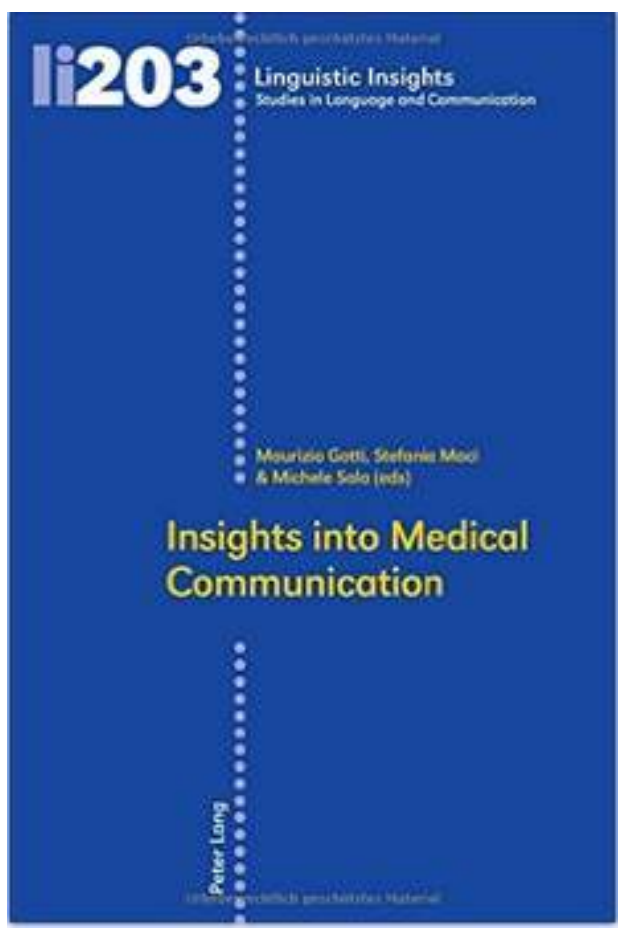
(patients, laypersons), have drawn the attention of researchers. Although recent studies (Myers 2010) have explored these new avenues of research, much remains to be done, all the more so as the pace at which new Internet technologies and social media are assuming new shapes is very challenging. That is why we have every reason to welcome the publication of Insights into Medical Communication, the 203rd volume of the Peter Lang "Linguistic Insights" series, co-edited by Maurizio Gotti, Stefania Maci and Michele Sala. It is worth noting that the aim of this series is

[...] to promote specialist language studies, both in the fields of linguistic theory and applied linguistics, by publishing volumes that focus on specific aspects of language use in one or several languages and provide valuable insights into language and communication research. A cross-disciplinary approach is favoured and most European languages are accepted. ${ }^{1}$

\section{Editorial characteristics}

2 This volume is made up of collected papers assembled from plenary talks and workshop presentations given at the Bergamo University International Conference hosted by Cerlis (The Language of Medicine: Science, Practice and Academia, 19-21 June 2014). ${ }^{2}$ It begins with a general introduction signed by the co-editors, followed by an introductory article written by Srikant Sarangi, one of the Bergamo conference plenary speakers. The rest of the book comprises sixteen individual or co-authored contributions, distributed into four sections dealing with communication in medical practice, communication with patients, the communication of healthcare information and research findings. In addition to the collection of papers, notes on contributors are also available. The target language of the book is English, but it is interesting to note that, within the collected papers, two chapters devoted to contrastive studies include documents in Portuguese (pp. 145-152) and in Italian (pp. 170-181). The contributors 
come from various fields of enquiry (rhetoric, philology, linguistics and translation, specialised discourse analysis, media language and communication, the study of online genres) and they share a common interest in applied linguistics, corpus-based studies and critical discourse analysis. Most of the contributors are either experienced ESP teachers or researchers, but not all of them are specialists of medical discourse. As a matter of fact, several have specialised in academic or legal discourse, and one of them is a member of the medical profession; all of this is in keeping with the crossdisciplinary approach advocated in the "Linguistic Insights" series.

\section{Introduction}

3 The useful general introduction signed by the three co-editors not only presents the introductory chapter and the sixteen contributions, but also provides the reader with an overview of some of the most significant recent research work carried out in the area of medical communication studies, laying special emphasis on the "open genre network" theory put forward by Swales and Feaks (2000), the theory of social interactions developed by Hyland (2004) and the ethnographic approach to discourse analysis advocated by Roberts and Sarangi (2005). The reader will also find a precious update on the development of Web-based technology and its sociolinguistic implications (Myers 2010). Above all, it highlights the transdisciplinary richness of the mosaic of viewpoints presented in this collection of papers.

4 Srikant Sarangi's introductory article, titled "Experts on experts; sustaining communities of interest", raises the question of the much-needed collaborative work that critical analysts and healthcare professionals should engage in. The author provides a theoretical introduction to various interpretive frameworks in the healthcare setting. His starting point is the notion of "interpretive variability" introduced by Gilbert and Mulkay (1984). Sarangi claims that, although crossdisciplinary collaboration between experts is badly needed to try to iron out variability, it can be plagued by ontological and epistemological differences. After distinguishing between the notions of communities of practice, discourse and interpretation, the author introduces the key concept of "communities of interest, which acknowledges differences in ontologies and epistemologies across given communities of practice/ discourse/interpretation, but privileges the mutual interest in the phenomena under study." (p. 28). The tensions, as well as the advantages induced by such a challenging approach, are illustrated by the presentation of exchanges between a discourse analyst and healthcare professionals involved in genetic counselling. According to the author, dialectical interaction and interpretive adjustment are key, and collaborative interpretation is probably the best way to minimise what he calls the "analyst's paradox" (p.33).

\section{Communication in medical practice}

5 The first section of the book is divided into four chapters. The first two contributions address the issue of social media (more particularly the use of Twitter) within the context of medical practice. The other contributions are more clinically-oriented and deal with communicative issues that have led to misdiagnoses in the field of psychiatry. 
6 In "Social media and professional practice in Medical Twitter", Greg Myers, who was one of the plenary speakers at the Cerlis conference, is continuing an invigorating wide-ranging research project on the development of social media, taking the Webbased genre of medical tweets as a case study. His corpus-based analysis of a set of tweets from six UK medical professionals is aimed at illustrating communication strategies and the range of modes offered by this community-forming tool. After referring to the interactions and the three types of discourse (personal, professional and institutional) described by Roberts and Sarangi (1999), the author introduces the civic concept of "public discourse/mode" (p. 53), aimed at raising the awareness and influencing attitudes of community members involved in Web-based communication. By analysing keywords and key semantic categories, Myers reaches the conclusion that Medical Twitter can offer a useful insight into the way professionals act and interact when they are faced with tensions between their personal lives, their professional duties, institutional pressure and the public debates they take part in. Here, attention is paid to language markers such as the pronouns $I$ and We (in the personal and the professional modes), and collocations in which the singular form of the word patient is used as a modifier as in patient care or patient safety (in the institutional mode). The author also suggests that "most tweets by medical professionals can be seen as hybrid between modes." (p. 63). To conclude, Myers' article is methodically-written and his analysis, although based on a rather small corpus, definitely provides new and stimulating insights into an area of research that is still largely unexplored.

7 Anna Tereszkiewicz's contribution "Medical doctors on Twitter: How and why MDs tweet" echoes the previous article. In fact, part of the author's analysis is based on Myers' theoretical research work. Like Myers, the author pinpoints both benefits (particularly the richness and the diversity of Web-based communication) and problems (such as issues of patient privacy or reliability of information) related to the use of Twitter in healthcare communication. Her corpus comprises the profiles and tweets of ten medical professionals, which she studies using the critical analysis of discourse and stance provided by Myers $(2010,2014)$. Her exploration is centered on three key phases of twittering, namely updates, addressed messages and retweets. Although the part devoted to stance-taking remains largely descriptive, it is useful as it shows some of the strategies tweeters develop to express stance, especially through epistemic and deontic modality. The author concludes by stating that "finally, Twitter serves as a tool of self-promotion, enhancement of identity as a medical doctor/ researcher." (p. 89). One very satisfying feature of this contribution is the multimodal approach adopted by the author in the study of audiovisual elements and hyperlinks, which are more and more commonly used in medical tweets.

Contrary to the previous contributions, the other chapters are centered on actual case studies and clinical observation in the field of psychiatry-related illnesses. Although the authors' goal is to analyse medical terminology and salient aspects of socio-medical communication, their analyses are not based on large electronic corpora, but on transcribed handwritten case notes on the one hand, and a patient's medical chart and video interview on the other hand.

In this section, the inclusion of a chapter in which the authors provide a retrospective historical analysis is a welcome contribution to the study of communication in medical practice. Carol Berkenkotter, Cristina Hanganu-Bresch and Kika Dreher, in "Descriptive psychopathology in asylum case histories: The case of Horatio Baldwin", focus on the 
case study of a patient suffering from manic episodes in early 20th century England and whose diagnosis of Manic Depression Insanity (MDI) was only made twenty years after the presentation of the symptoms on account of terminological misunderstanding. The study starts off with a very useful presentation of German psychiatrist Emil Kraepelin's definition of MDI at the turn of the century, along with the description of the telltale symptoms of the illness, namely mania and depression alternating with periods of lucidity. Referring to the concept of "enregisterment" (p. 93), to which they prefer the term "uptake", the authors carefully document the slow impregnation of the new terminology in the British psychiatric community. After transcribing and coding the seventy original case notes written by Baldwin's psychiatrists at the time, they present two charts showing the longitudinal evolution and organisation of the main symptoms of the illness. The article ends on the assumption that the linguistic representation of the notion of MDI helped psychiatrists to conceptualise its symptoms and thus, made its diagnosis easier.

10 In "Dialectical variation and miscommunication in medical discourse: A case study", Syelle Graves, Rebecca Burson and Victor Torres-Collazo study a case of psychiatric misdiagnosis from a synchronic viewpoint. An African-American woman speaking African-American Vernacular English (AAVE) presented with stiff muscles, emotional symptoms and repeated falls and was (mis)diagnosed with anxiety for several years before Rebecca Burson, one of the co-authors, made the final diagnosis of Stiff Person Syndrome (SPS). The authors suggest that misdiagnosis may be due to linguistic and cultural factors that lead to dialect discordance. After presenting a review of the literature on language variation and dialect discordance, they concentrate on conventional medical training words associated with SPS. Their critical analysis of the patient's chart (p. 121) underpins the contrast between petrified medical terminology (for instance "Tree trunk fall") and the patient's own words ("I'm having problems with falling"). The retrospective chart review that follows (pp. 122-124) confirms the social/ ethnic prejudices that doctors who do not belong to the patient's community might have. Analysis of the post-diagnosis video of the patient shows that her speech style and stylistic variants were most probably a source of communicative confusion. Beyond the originality of this individual case study, these findings open interesting perspectives for improving the language taught in medical school training to ensure that ethnic considerations and class background are no longer a discriminating factor in medical communication.

\section{Communicating with patients}

11 The second section, which is made up of four chapters, moves on to more institutional issues. The first two chapters are devoted to the contrastive study of a specific genre, Patient Information Leaflets (PILs); the languages involved are English, Portuguese and Italian. The other chapters offer a multimodal discourse analysis of direct-to-consumer drug advertisements and online self-care communication; both studies focus on the interplay between written text and graphic or visual elements.

12 The point of view of the first contribution is overtly multilingual. In "Attempting the easification of Patient Information Leaflets (PILs) in Brazil", Celina Frade compares the English and Brazilian versions of the same texts. The study starts off with a presentation of the institutional and discursive framework of Brazilian PILs, which are 
regulated by the national health surveillance agency (ANVISA), and continues with a detailed description of their generic structure. The author then examines the concept of "easification" (p. 144) formulated by Bhatia (1983), with a view to checking whether clarity and health literacy are effective. She presents her attempts to easify three items (originally adapted by linguists) taken from an updated Brazilian PIL that accompanies the generic drug Alprazolam. The author's contrastive analysis is particularly relevant, but it is regrettable that some of the grammatical or lexical mistakes present in the original English version were overlooked in the author's adaptation. Nevertheless, the interest of this particular contribution not only lies in its bilingual contrastive approach but also its proposal to create a task force of expert linguists and users to explore further easification procedures.

The second contribution is also an analysis of the popularisation of medical discourse in the genre of PILS. In “'Can you read this leaflet?': User-friendliness of Patient Information Leaflets in the UK and in Italy", Rosita Maglie compares sixty-five "PILs of the month" taken from the UK PIL corpus with their Italian counterparts. The chapter starts with general background information on PILs; special emphasis is laid on the legal requirements that regulate their production, their simplification and their translation into EU languages other than English. The passage from expert-to-expert text to the final version of the layperson-oriented PIL is highlighted. By carrying out a corpus-based investigation of the English texts, the author pinpoints the rhetorical, terminological and structural strategies that are used to facilitate text readability. Then, she examines three drug categories (OTC drugs, OTCs with medical advice, prescription drugs) by comparing English and Italian versions of the same texts. The chapter concludes on the observation that, due to differences in cultural and epistemological backgrounds, Italian PILs are generally less user-friendly than UK ones, and that, in order to improve popularisation of Italian PILs, patients should be consulted so as to implement necessary changes.

In the third contribution, "Patient (mis)understanding of prescription drug ads in social media: Multimodal Discourse Analysis of eDTCA", Anna Franca Plastina considers "the manner in which multimodal texts convey risk and benefit information and the way in which semiotic representations may cause distraction." (p. 196). Through a useful analysis of twenty-four YouTube videos posted by pharmaceutical companies, the author presents the main characteristics of electronic Direct-To-Consumer Advertising (eDTCA) and offers a critical analysis of this consumer-oriented, Webmediated genre. First, she presents a review of the literature which shows that such ads are mainly driven by promotional purposes and that the information that is provided might be asymmetric and unfair in terms of risk/benefit evaluation. Using Multimodal Discourse Analysis methodology (Kress 2010), she then goes on to examine the parallel use of written, audio and visual semiotic modes and ferrets out semiotic distractors by analysing several visual metaphors. The author concludes that the presentation of risks and benefits of medical products is not balanced since risk information is systemically toned down whereas benefit information is highlighted. Besides offering a stimulating study of the interplay between different semiotic systems, this research provides useful leads for a discussion about the educational role of eDTCA within the context of Webmediated self-care.

15 The fourth chapter of this section, "Empowering patients to self-care in Web-mediated communication: A Multimodal Discourse Analysis", written by Girolamo Tessuto, also 
focuses on the interaction between written texts and visuals. Referring to Kress and van Leeuwen (1996), the author examines data extracted from the UK-based Self-Care Library website developed by professional health teams to provide both patients and health care professionals with online medical resources. After a presentation of the content and general layout of the site, attention is paid to language markers such as personal pronouns $(I / y o u / w e)$, the incidence of exhortative imperatives, the communicative function of questions, the role played by active/passive structures and epistemic and deontic modal verbs, and the use of domain-specific adjectives. The last addition to this study consists of an analysis of the interactive function and the compositional meaning of visuals images in the Home Page. The author suggests that the linguistic and visual features of the text "are used to construct direct concern and contact with the individual readers as patients, who are encouraged to become active agents [...] in the communication activity via the Web." (p. 233).

\section{Communicating healthcare information}

The third section comprises three chapters which deal with Internet-mediated communication and the transmission of prevention-oriented healthcare information. Most of the texts selected for critical analysis are targeted at either young people or gamblers, and are taken from the websites of institutional agencies or registered charities.

In "Living with diabetes: The discourse of medical information on the Internet for young people", Judith Turnbull explores the transfer of domain-specific information concerning diabetes and its prevention within the context of two UK websites aimed at children and teenagers. First, the author observes that, thanks to the development of Web 2.0, healthcare information is no longer strictly distributed in a top-down fashion, from expert to non-expert, but can circulate in a user-to-user mode, in which individuals take a more active part in medical decisions. This paradigmatic shift has induced new communicative strategies so that the medical message can get across to young people. After a useful review of the literature on the cognitive and communicative aspects of knowledge transfer (Moirand 2003) and the popularisation of professional discourse (Hyland 2010), the author moves on to a contrastive study of the strategies used in the teenagers' and adults' sections of the charity-registered website. Then, she examines the teenagers' and the children's section of the two websites to compare their respective discursive strategies. Readers will appreciate the crystal-clear analysis of the strategic approaches brought to light by the author, who notes that, cognitively speaking, the teenagers are provided with a lighter information load than adults, while, from a communicative viewpoint, the interpersonal and emotional dimensions are emphasised in both the teenagers' and the children's sections.

In "The Representation of gambling in gambling awareness campaigns: The discursive construction of addiction", Paola Catenaccio offers a study of the implications of rhetorical and linguistic representations of gambling in awareness-raising campaigns conducted in the USA, Canada and Australia. In a first step, the author describes the shift from the twentieth-century notion of gambling, perceived as a morally reprehensible flaw, to pathological gambling seen as an institutional illness (from 1980 onward). In view of this evolution, she argues that "[d]iscourse plays a key role both in the social construction of illness and in the pathologization of deviance [...]" (p. 270). 
Then, the study focuses on institutional communication via the discursive strategies implemented in the course of three different prevention campaigns. The findings of the study highlight the way terminological changes illustrate the shift from moral deviance to medical condition or even safe behavior. Thus, depending on its social and discursive construction, gambling can be regarded as a major ("pathological gambling") or a minor ("responsible gambling") problem, not to mention the politically-correct term ("gaming"), which seems to have been coined to protect the vested interests of some states or institutions. Finally, the analysis of the Canadian and Australian campaigns shows that the medicalisation of gambling can also be interactionally constructed or de-stigmatised to help gamblers kick the habit.

The last chapter of this section describes how UK and US government agencies address the question of healthy eating for children. In "Authority and solidarity: How institutional Websites in the US and the UK communicate nutritional guidelines", Miriam Bait explores the structure of dietary guidelines taken from the websites of several public agencies. Using Fairclough's critical analysis framework (1995), the author's main aim is to analyse communicative strategies and the ideological construction of discourse in a body of UK and US samples. After presenting the lexical patterns of the texts, which usually correspond to general discourse, she studies the shift from the original power wielded by institutions to the progressive empowerment of citizens through both new forms of representation and semantic choices. The study ends by concluding that, in the US texts, solidarity is highlighted since children and parents are involved in the obesity risk awareness campaigns whereas, in the UK texts, a more informative, less emphatic approach is adopted. Contrary to the previous contributions, this chapter remains largely descriptive and one may regret that its theoretical scope should not be broader.

\section{Communicating research findings}

The final section of the volume is composed of five chapters centered on scientific and medical research. Interestingly, the various contributions consider how conventional research structures are re-contextualised in social media. The section covers a wide range of media which includes online press releases, weblogs and research letters.

21 The first chapter offers a study of variations of discourse and content matter when scientific news is transformed by different media genre conventions. In "Media representations of scientific research findings: From 'stilbenoids raise CAMP expression' to 'red wine protects against illness"', Ruth Breeze illustrates this transformation by comparing the main discursive features of three types of media; the original article of an Oregon State University laboratory, the online press release issued by the same university disclaiming that the results published in the article may have immediate human applications, and three UK news stories written in the wake of the disclaimer. Based on the concepts of "engagement" and "graduation" developed by Martin and White (2005), the study focuses on the dialogic relationship between each media and the (actual or potential) readers. The author shows that the online press release and the article from the UK quality newspaper (the Daily Telegraph) display signs of both intensification and hedging, and that they are aimed at scientifically-minded readers. On the other hand, the two news stories taken from the UK tabloids (the Daily Express and the Mirror) rely mainly on assertion and seem to be written for uncritical 
readers. Although the sample of texts considered here is rather small, this is a fruitful line of research that should be followed up.

María José Luzón's chapter, titled "Recontextualizing expert discourse in Weblogs: Strategies to communicate health research to experts and the interested public", examines the Web-mediated interplay between experts/bloggers and their audiences. It offers a corpus-based analysis of the popularisation of peer-reviewed academic discourse in seventy-five international blogposts taken from the site $<$ ResearchBlogging.org>. Using the methodological frameworks provided by Calsamiglia and van Dijk (2004) and Hyland (2010), the author explores the concepts of "recontextualisation" and "proximity" to analyse the corpus. She highlights the importance of hyperlinks, visuals, explanations and the use of metaphors in the process of recontextualisation and in the popularisation of specialised discourse. Readers will appreciate the inclusion of several useful tables (pp. 335-340) which illustrate the way medical research information is tailored to the needs of interested readers.

In the next contribution, "Semantic sequences and the pragmatics of medical research article writing", Davide Mazzi looks at co-occurring items in the four typical parts of the IMRD structure of authentic medical research articles. Based on the corpus-driven pedagogic grammar of Hunston and Francis (1998), the author examines a synchronic corpus of 280 research articles from international medical journals. An analysis is made in terms of closed-class grammar words and grammar patterns, especially the $N$ that pattern (p. 356). The author highlights several recurring co-occurring items such as the "for patients with +'Disease" pattern in the Introduction section or "the verb of 'continuity' + our hypothesis that" pattern in the Discussion section. The interest of this particular chapter lies in its innovative pedagogic proposal and the promising didactic perspectives it opens since the author encourages language instructors to adopt a sequence-based grammatical approach to help budding medical researchers master typical co-occurrence patterns in specialised language.

The fourth chapter by Stefania M. Maci, titled "Health slips as the financial crisis grips': Tensions and variations in medical discourse", gives an account of the increasingly marked business approach to medical research and the resulting changes in medical discourse. It is argued that the formal genre of the medical research article has hybridised to form a new, more compact genre, the research letter, i.e. "primary papers of exceptional clinical importance and urgency" (p. 376) aimed at facilitating the rapid dissemination of key scientific findings. After referring to the definition of the concept of New Public Management (NPM), which is linked to today's global crisis, the author analyses a corpus of fifty research letters selected from a British journal (The Lancet) and a North American journal (JAMA). The corpus-driven analysis reveals that lexical elements such as Medicare, costs or funding and the lexical stem manage* are statistically significant in research letters, which pinpoints the impregnation of NPM discourse. The author concludes that, due to rapid competitive publishing and changes in medical governance, domain-specific contents and discourse are modified by economic and corporate factors. This contribution convincingly shows that corpus linguistics can provide a useful basis for critical genre and discourse analysis as applied to medical writing.

25 In the final chapter of this section, "Knowledge dissemination in genetics blogs", Anna Stermieri also explores the way medical knowledge is disseminated thanks to the interactive advances offered by Web 2.0 communication. The author focuses on the 
domain-specific area of genetics and studies a corpus of four academic weblogs written by scientists and taken from the GeneBlog Corpus. A second reference corpus, the BLOGcorpus, is used to generate a list of typical lexical items to be compared with the post section of the GeneBlog Corpus. The investigation of some of the corpus keywords, such as risk and disease and their collocates, reveals that bloggers tend to recontextualise medical items, for instance eponymous collocations like Crohn's disease, with a view to popularising their discourse while they do not explain more general expressions such as genetic/complex disease because they are more research-oriented. Thus, it is worth noting, along with the author, that in spite of their hybrid position as both medical experts and scientific researchers, geneticists/bloggers resort to innovative discursive strategies to try and bridge the gap between experts and lay audiences.

\section{Concluding remarks}

All in all, Insights into Medical Communication is a book that offers both theoretical issues and pedagogic perspectives for researchers and teachers of ESP. One of the richest aspects of the volume is its cross-disciplinary presentation of current critical discourse analysis research, with special emphasis on the multisemiotic nature of multimodality in e-communication. As the title implies, it is not a book for healthcare professionals only, but it provides new and stimulating updates and insights into the way members of the medical community at large (medical students, medical doctors, healthcare providers, pharmaceutical companies, medical institutions, patients, interested laypeople) communicate. The collection of essays is extremely coherent thanks to its rigorous thematic classification and the systematic use of critical discourse analysis tools and methods. Precisely because of this methodical presentation, some readers might complain of a certain degree of redundancy if they decide to read the volume as a whole, but this is to be regarded as a minor flaw. Except for a few misprints such as "tin solder" (p. 120), "epato-cellular deficiency" (p. 174) or "Sematic categories" (p. 395), the editing is particularly careful. Nevertheless, in a book that highlights and praises clarity of communication, it is to be noted that some of the figures (pp. 170, 173, 179, $180,181)$ are far from being easy to read. Keeping these minor criticisms in mind, it can be said that, thanks to the volume's clear and solid theoretical and methodological foundations, it is likely that doctoral students and, as a matter of fact, all researchers in applied linguistics will benefit from it. It may be added that the volume also holds an interest for non-professional and non-academic readers who wish to have useful insights into medical communication.

\section{BIBLIOGRAPHY}

BHATIA, Vijay K.1983. "Simplification vs. easification: The case of legal texts". Applied Linguistics $4 / 1,42-54$. 
CALSAMIGLIA, Helena \& Teun VAN DIJK. 2004 "Popularization discourse and knowledge about the genome". Discourse \& Society 15/4, 369-389.

FAIRCLOUGH, Norman. 1995. Critical Discourse Analysis: The Critical Study of Language. London: Longman.

GILBERT, Nigel \& Michael MULKAY. 1984. Opening Pandora's Box: A Sociological Analysis of Scientists' Discourse. Cambridge: Cambridge University Press.

GOTTI, Maurizio \& Françoise SALAGER-MEYER (eds.). 2006. Advances in Medical Discourse Analysis: Oral and Written Contexts. Bern: Peter Lang.

HUNSTON, Susan \& Gill FRANCIS. 1998. "Verbs observed: A corpus-driven pedagogic grammar". Applied Linguistics 19/1, 45-72.

HYLAND, Ken. 2004. Disciplinary Discourses: Social Interactions in Academic Writing. London: Longman.

HYLAND, Ken. 2010. "Constructing Proximity: Relating to Readers in Popular and Professional Science". English for Academic Purposes 9/2,116-127.

KRESS, Gunther. 2010. Multimodality: A Social Semiotic Approach to Contemporary

Communication. London: Routledge.

KRESS, Gunther \& Theo VAN LEEUWEN. 1996. Reading Images: The Grammar of Visual Design. London: Routledge.

MARTIN, James R. \& Peter R. R. WHITE. 2005. The Language of Evaluation: Appraisal in English. London: Palgrave Macmillan.

MOIRAND, Sophie. 2003. "Communicative and cognitive dimensions of discourse on science in the French mass media". Discourse Studies 5/2, 175-206.

MYERS, Greg. 2010. The Discourse of Blogs and Wikis. London: Continuum.

MYERS, Greg, 2014. "Social media, scientific research and professional practice”. Paper presented at the Cerlis 2014 Conference "The Language of Medicine: Science, Practice and Academia". Bergamo: 19-21 June 2014.

ROBERTS, Celia \& Srikant SARANGI. 1999. "Hybridity in gatekeeping discourse: Issues of practical relevance for the researcher". In SARANGI, S \& C. ROBERTS (eds.), Talk, Work and Institutional Order. Berlin: Mouton de Gruyter, 473-504.

ROBERTS, Celia \& Srikant SARANGI. 2005. “Theme-oriented discourse analysis of medical encounters". Medical Education 39, 632-640.

SWALES, John M. \& Christine B. FEAK. 1994. Academic Writing for Graduate Students: Essential Tasks and Skills: A Course for Non-native Speakers of English (English for Specific Purposes). Ann Arbor: University of Michigan Press.

TAAVITSAINEN, Irma \& PÄivi PAHTA (eds.). 2004. Medical and Scientific Writing in Late Medieval English. Cambridge: Cambridge University Press.

TAAVITSAinen, Irma \& PÄivi PAHTA (eds.). 2011. Medical Writing in Early Modern English. Cambridge: Cambridge University Press. 
NOTES

1. See Peter Lang site <http://www.peterlang.com/index.cfm? event $=\mathrm{cmp} . \mathrm{ccc}$.seitenstruktur.detailseiten\&seitentyp=series\& $\mathrm{pk}=402 \&$ concordeid $=\mathrm{LI}>, \quad$ last accessed on August 15 $5^{\text {th }}, 2015$.

2. See Cerlis site <dinamico.unibg.it/cerlis/page.aspx?p=263>.

\section{AUTHORS}

\section{JEAN-PIERRE CHARPY}

Université de Bourgogne Franche-Comté, EA 4182. Jean-Pierre.Charpy@u-bourgogne.fr 